\title{
Non-Aqueous Approach to Synthesize Amorphous/Crystalline Metal Oxide-Graphene Nanosheet Hybrid Composites
}

\author{
Xiangbo Meng, Dongsheng Geng, Jian Liu, Mohammad Norouzi Banis, Yong Zhang, \\ Ruying Li, and Xueliang Sun* \\ Department of Mechanical and Materials Engineering, The University of Western Ontario, \\ London, Ontario N6A 5B8, Canada
}

Received: June 24, 2010; Revised Manuscript Received: September 10, 2010

\begin{abstract}
Presently, there is a dramatically increasing interest in developing graphene-supported nanocomposites, due to their unprecedented properties. Apart from the methods exposed in previous studies, this work presents a nonaqueous approach of using atomic layer deposition (ALD) to constitute novel metal oxide-graphene hybrid nanocomposites based on graphene nanosheet (GNS) powders. It is demonstrated that this gas-solid strategy exhibits many unique benefits. It reports for the first time that the as-prepared $\mathrm{SnO}_{2}$-GNS nanocomposites are featured with not only tunable morphologies but controllable amorphous and crystalline phases of $\mathrm{SnO}_{2}$ component as well, using $\mathrm{SnCl}_{4}$ and $\mathrm{H}_{2} \mathrm{O}$ as the ALD precursors. Furthermore, the determinant factors and underlying mechanisms were outlined and discussed in this work. As a consequence, besides the demonstration of ALD as an important approach for nanoarchitecturing novel metal oxide-GNS composites, the as-synthesized $\mathrm{SnO}_{2}$-GNS hybrid nanocomposites provide more choices for many important applications, such as lithiumion batteries, solar cells, and gas sensing.
\end{abstract}

\section{Introduction}

Interest in nanocomposites is ever-growing, ascribed to their peculiarities in combining desirable properties of hybrid nanosized building blocks for a given application. In this way, carbon nanotubes (CNTs), being excellent one-dimensional (1D) candidates, have been extensively incorporated in a wide range of nanocomposites for many applications. ${ }^{1-4}$ Presently, following CNTs, graphene being a $2 \mathrm{D}$ nanoscale building block is attracting more and more effort toward developing novel nanoarchitectured composites since its discovery ${ }^{5}$ in 2004 . To date, graphene (or graphene stacks, a few layers of graphene) has been reported to incorporate with three main types of materials: polymers, ${ }^{6-9}$ metals, ${ }^{10-13}$ and metal oxides, ${ }^{14-20}$ covering a series of applications (including field emitters, photocatalysis, conductors, supercapacitors, fuel cells, and batteries, etc.) with improved mechanical, electrical, optical, or electrochemical properties. For metal oxide-graphene nanocomposites (MO-GNCs), however, only limited cases were exposed in literature and they were prominently synthesized in aqueous solutions via two routes: wet chemical deposition, ${ }^{15-19}$ and solution-based mechanical mixing. ${ }^{20}$ The former route was generally carried out with a complicated and tedious process, accounting for several tens of hours. ${ }^{15-19}$ As an alternative, the latter one was simply performed through mechanically mixing available metal oxide nanoparticles with graphene dispersions, ${ }^{20}$ having less manipulation on metal oxide nanopartilces and thereby lacking of flexibility and precision as a synthesis strategy. Commonly, the aqueous solution-based methods exposed in literature show inability to precisely control the morphologies and structures of metal oxides.

With attempts to circumvent the above-mentioned issues, recently we successfully fulfilled the synthesis of MO-GNCs via a nonaqueous approach and the first case will be reported

* To whom correspondence should be addressed. E-mail: xsun@ eng.uwo.ca. in this work. This strategy is featured by applying the technique of atomic layer deposition (ALD) to deposit metal oxides on graphene nanosheet (GNS) powders. Our studies demonstrated that this approach can provide a precise fabrication of MOGNCs with more benefits, opening a potential avenue for mass production. Characteristically, ALD is a surface-controlled gas-solid process and uniquely performed by two sequentially cyclic half-reactions. ${ }^{21}$ In comparison to wet chemical routes as well as traditional chemical and physical vapor deposition, ALD contributes to a controllable, uniform, and conformal deposition at the atomic level, ${ }^{21}$ and is going into a fashion in nanotechnology to synthesize novel nanostructures and nanodevices. ${ }^{22,23}$ In addition, ALD has the capability to deposit both inorganic (metals and metal oxides) ${ }^{24}$ and organic materials (polymers). ${ }^{21}$ In the case of $\mathrm{SnO}_{2}$, it has mainly been performed on flat substrates (e.g., quartz glass) via $\mathrm{ALD}^{25-27}$ using $\mathrm{SnCl}_{4}$ and $\mathrm{H}_{2} \mathrm{O}$ as well as other precursors. The reaction between $\mathrm{SnCl}_{4}$ and $\mathrm{H}_{2} \mathrm{O}$ is fairly straightforward with the product of $\mathrm{SnO}_{2}$, as described in the following Reaction 1.

$$
\mathrm{SnCl}_{4}+2 \mathrm{H}_{2} \mathrm{O} \rightarrow \mathrm{SnO}_{2}+4 \mathrm{HCl}
$$

In the ALD of $\mathrm{SnO}_{2}\left(\mathrm{ALD}-\mathrm{SnO}_{2}\right)$, however, Reaction 1 was replaced with two sequential half-reactions as suggested by the following: ${ }^{28}$

$$
\begin{gathered}
\mathrm{I}-\mathrm{OH}+\mathrm{SnCl}_{4}(\mathrm{~g}) \rightarrow \mathrm{II}-\mathrm{O}-\mathrm{SnCl}_{3}+\mathrm{HCl}(\mathrm{g}) \\
\mathrm{II}-\mathrm{Cl}+\mathrm{H}_{2} \mathrm{O}(\mathrm{g}) \rightarrow \mathrm{II}-\mathrm{OH}+\mathrm{HCl}(\mathrm{g})
\end{gathered}
$$

where the symbol II denotes the substrate surface, and (g) refers to gas phase species. One "A" pulse of $\mathrm{SnCl}_{4}$ (Reaction 2-A) and one following " $\mathrm{B}$ " pulse of $\mathrm{H}_{2} \mathrm{O}$ (Reaction 2-B) consist of 


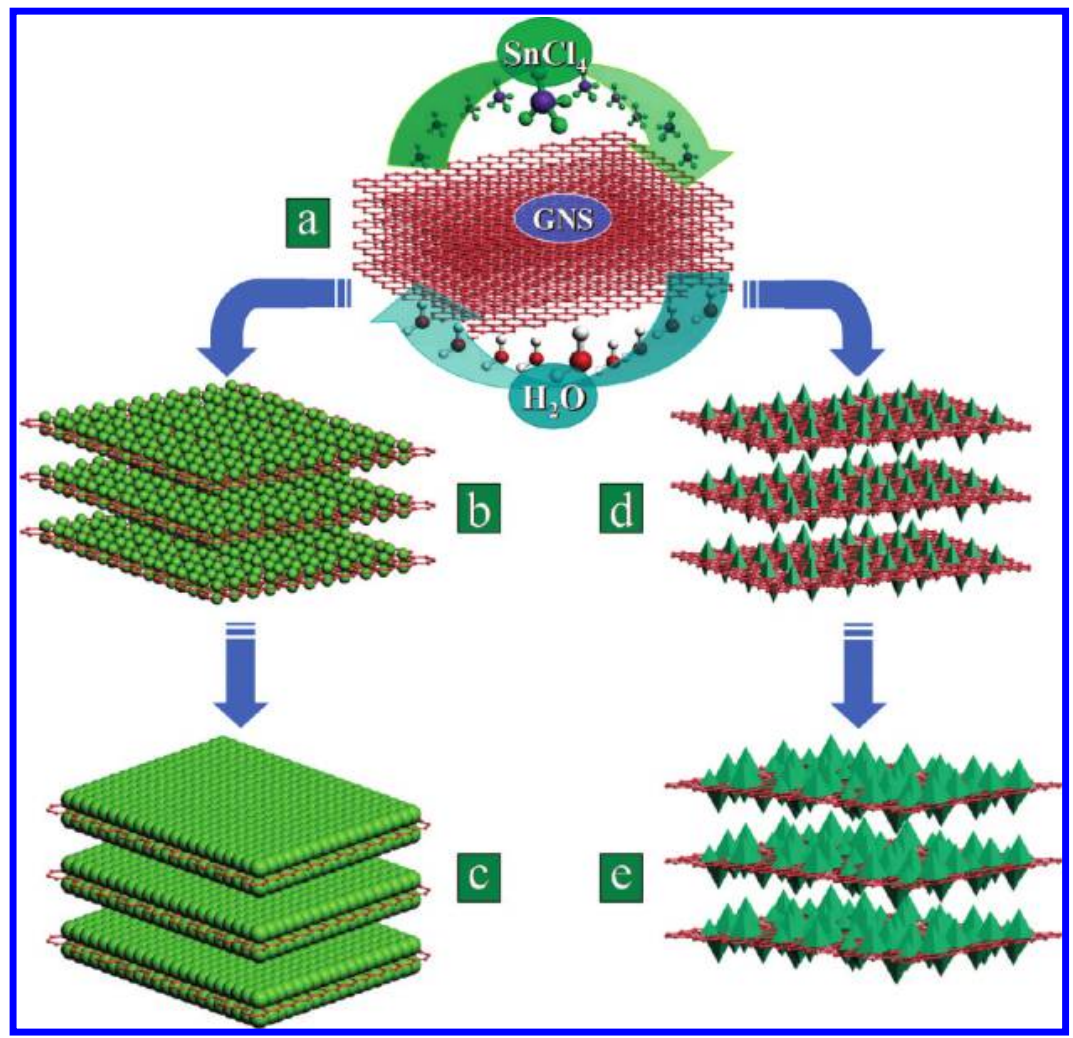

Figure 1. Schematic illustration of the precise approach to tune the morphology and amorphous-crystalline phases via atomic layer deposition technique (ALD). (a) ALD-SnO 2 process employed on graphene nanosheets (GNS) using $\mathrm{SnCl}_{4}$ and $\mathrm{H}_{2} \mathrm{O}$ as the two precursors to form amorphous/ crystalline $\mathrm{SnO}_{2}$-GNS nanocomposites; (b) uniformly distributed amorphous $\mathrm{SnO}_{2}$ nanoparticles on GNS surface; and (c) amorphous $\mathrm{SnO}{ }_{2}$ thin film formed on GNS surface by growing nanoparticles; (d) small crystalline $\mathrm{SnO}_{2}$ nanoparticles uniformly distributed on GNS surface; and (e) large $\mathrm{SnO}_{2}$ nanoparticles uniformly distributed on GNS surface with higher density.

one typical "A-B" cycle in ALD process, and the cycling of "A-B" half-reactions can build up $\mathrm{SnO}_{2}$ films increasing with accuracy at the atomic level. In this work, we deduce this ALD strategy through exemplifying the synthesis of $\mathrm{SnO}_{2}$-GNS composites, using $\mathrm{SnCl}_{4}$ and $\mathrm{H}_{2} \mathrm{O}$ as the ALD precursors.

The successful demonstration of $\mathrm{ALD}-\mathrm{SnO}_{2}$ on GNS produced 3-D nanoarchitectured networks of $\mathrm{SnO}_{2}$-GNS composites. More importantly, the composites are featured with tunable morphologies and controllable phases of the $\mathrm{SnO}_{2}$ component. It was found that the $\mathrm{SnO}_{2}$ component can present amorphous and crystalline phase through suitably adjusting the growth temperature. In addition, due to the cycling nature of ALD, the synthesis of $\mathrm{SnO}_{2}$-GNS nanocomposites also showed a characteristic on precisely controlling the morphologies of asdeposited $\mathrm{SnO}_{2}$. Thus, this work is significant with respect to three main outcomes: (i) ALD was for the first time suggested and successfully demonstrated as an efficient strategy to synthesize MO-GNCs; (2) the as-synthesized nanocomposites of $\mathrm{SnO}_{2}$-GNS presented fine-tuned morphologies; and (3) wellcontrolled structural phases from amorphous to crystalline $\mathrm{SnO}_{2}$. To highlight the outcomes from this nonaqueous approach, we used a schematic illustration to help readers understand, as shown in Figure 1. The ALD- $\mathrm{SnO}_{2}$, as illustrated by Figure 1(a), is fulfilled by two sequential half reactions induced by $\mathrm{SnCl}_{4}$ and $\mathrm{H}_{2} \mathrm{O}$, respectively. At a low growth temperature $\left(200^{\circ} \mathrm{C}\right)$, amorphous $\mathrm{SnO}_{2}$ nanoparticles (Figure 1(b)) were uniformly formed on GNS in initial ALD cycles. The nanoparticles grew bigger and finally coalesced into a thin film (Figure 1(c)) with increased ALD cycles. At a high temperature $\left(400{ }^{\circ} \mathrm{C}\right)$, however, crystalline $\mathrm{SnO}_{2}$ nanoparticles were deposited on GNS and grew from small sizes (Figure 1(d)) to large ones (Figure 1(e)) with increased ALD cycles. Furthermore, the underlying mechanisms responsible for controllable structural phases of $\mathrm{SnO}_{2}$ were also explored in this work based on surface chemistry.

\section{Experimental Section}

2.1. Preparation of GNS. For preparation of GNS, we first oxidized natural graphite powder (45 $\mu \mathrm{m}, 99.99 \%$, SigmaAldrich as shown in Figure SI-1(a) and (b), Supporting Information) using a modified Hummers method. ${ }^{29}$ In detail, graphite powder $(1 \mathrm{~g})$ was first stirred in concentrated sulphuric acid $(23 \mathrm{~mL})$ with a following addition of sodium nitrate $(0.5$ $\mathrm{g}$ ) at room temperature. The stirring lasted for $16 \mathrm{~h}$, and then the mixture was cooled down to $0{ }^{\circ} \mathrm{C}$. Thereafter, potassium permanganate $(3 \mathrm{~g})$ was added to form a new mixture. Two hours later, the mixture formed a green slurry around $35^{\circ} \mathrm{C}$, which was stirred for another $3 \mathrm{~h}$. Then, water $(46 \mathrm{~mL})$ was slowly added into the paste with an increased temperature around $98{ }^{\circ} \mathrm{C}$. The suspension was remained at this temperature for 30 min before it was further diluted with another addition of water and hydrogen peroxide $(140 \mathrm{~mL})$. In the following, the suspension was filtered and washed until the $\mathrm{pH}$ value of the filtrate was neutral. The as-received slurry is the so-called graphite oxide (GO, Figure SI-1(c) and (d), Supporting Information), which was further dried in a vacuum oven at $60^{\circ} \mathrm{C}$. To prepare GNS, the as-synthesized GO was first flushed by $\mathrm{Ar}$ for $20 \mathrm{~min}$ in a quartz tube. Then, the quartz tube was promptly moved into a Lindberg tube furnace with a preheated temperature around $1050{ }^{\circ} \mathrm{C}$. After $30 \mathrm{~s}$ thermal treatment, GO was reduced into expanded GNS powders as illustrated in Figure 2(a).

2.2. ALD-SnO $\mathbf{O}_{2}$. The as-synthesized GNS powder was first loaded into a commercial ALD reactor (Savannah 100, Cambridge Nanotechnology Inc., USA) preheated to a preset growth 

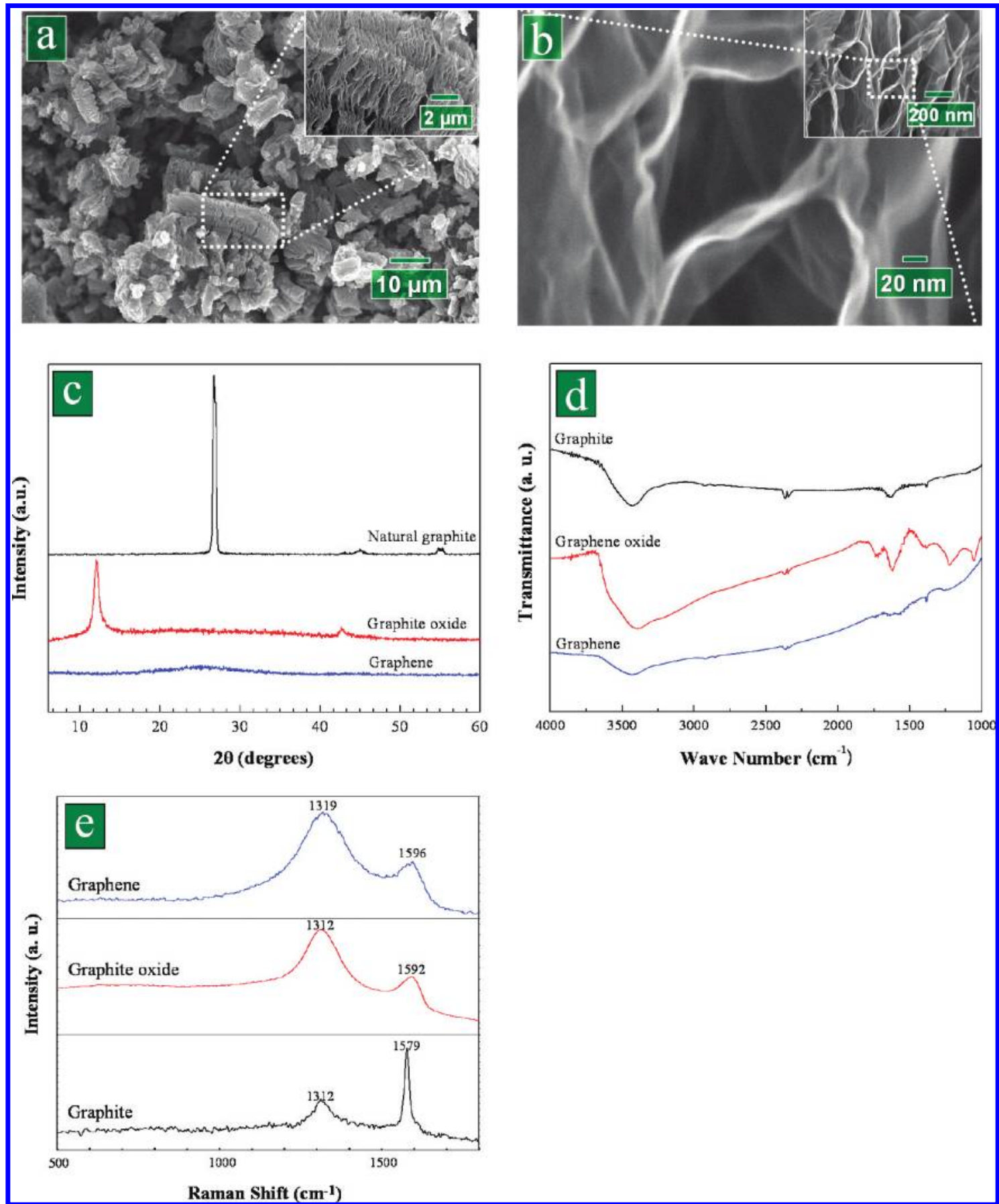

Figure 2. Characteristics of GNS: SEM images of (a) low magnification, and (b) high magnification; (c) XRD, (d) FTIR, and (e) Raman spectra.

temperature. In this study, two growth temperatures were applied, i.e., 200 and $400{ }^{\circ} \mathrm{C}$. The following $\mathrm{ALD}-\mathrm{SnO}_{2}$ was performed through introducing tin(IV) chloride $\left(99 \% \mathrm{SnCl}_{4}\right.$, Sigma-Aldrich) and deionized water $\left(\mathrm{DI} \mathrm{H}_{2} \mathrm{O}\right)$ into the ALD reactor in an alternating manner. In the ALD processes, nitrogen was selected in this study as the carrier gas with a flow rate of $20 \mathrm{sccm}$, and the ALD reactor was sustained at a low level of pressure (typically 0.4 Torr) with a vacuum pump (Pascal 2005 I, Adixon). The ALD procedures were set as follows: (1) a $0.5 \mathrm{~s}$ supply of $\mathrm{SnCl}_{4}$; (2) a $3 \mathrm{~s}$ extended exposure of $\mathrm{SnCl}_{4}$ to GNS; (3) a $10 \mathrm{~s}$ purge of oversupplied $\mathrm{SnCl}_{4}$ and any byproduct; (4) a 1 s supply of water vapor; (5) a 3 s extended exposure of water vapor to GNS; (6) a $10 \mathrm{~s}$ purge of oversupplied water and any byproduct. The aforementioned six-step sequence constituted one ALD-SnO 2 cycle and the ALD processes were adjusted with different cycling numbers.

2.3. Characterization. To characterize our samples' morphologies, structures, and compositions, we used field emission scanning electron spectrometry (FE-SEM, Hitachi 4800S) coupled with energy dispersive spectroscopy (EDS), transmission electron microscope (TEM, Philips CM10), high-resolution transmission electron microscope (HRTEM, JEOL 2010 FEG), $\mathrm{X}$-ray diffractometer (XRD, Inel multipurpose diffractometer), Raman spectrometry (RXN1-785, Kaiser Optical Systems InCo.), Fourier transform infrared spectroscopy (FTIR, Bruker Tensor 27), and the results are elucidated in the following sections. 


\section{Results and Discussions}

The GNS powders employed in our study were made from natural graphite powders via a series of processes. During the preparation, graphite powders were first oxidized using Hummers method ${ }^{29}$ with the product of graphite oxide (GO). Thereafter, GO was reduced via a rapid thermal expansion ${ }^{30}$ which separated the layered GO into partially functionalized GNS. The as-synthesized GNS powders were characterized by SEM, XRD, FTIR, and Raman, as illustrated in Figure 2. In contrast to the natural graphite and GO (Figure SI-1, Supporting Information), the GNS powders (Figure 2(a) and insert) present a fluffy worm-like porous structure. ${ }^{31}$ The porous "worms" are featured by numerous honeycombs (inset of Figure 2(b)) surrounded by wrinkles of typically less than $3 \mathrm{~nm}$ in thickness (Figure 2(b)). XRD spectra patterns (Figure 2(c)) clearly distinguished the as-synthesized GNS from the natural graphite as well as GO. Graphite has the strongest (002) peak at $26.8^{\circ}$ as well as three weak peaks of (100), (101), and (004) at $43^{\circ}$, $45^{\circ}$, and $55^{\circ}$, respectively. In comparison, GO shows a very strong (001) diffraction peak at $12^{\circ}$, suggesting that the interlayer distance increases and the structure is modified due to oxygenated groups, ${ }^{32}$ as well as a weak (100) diffraction peak around $43^{\circ}$. In contrast, the GNS received a broad diffraction (002) peak shifted back to $26.8^{\circ}$, implying that GO was reduced via the rapid thermal expansion and the extensive conjugated $\mathrm{sp}^{2}$ carbon network (i.e., the ordered crystal structure) was restored. ${ }^{33}$ FTIR spectra (Figure 2(d)) further clarified their differences in functional groups. It is easy to observe that the natural graphite mainly shows the stretching vibrations of hydroxyl $(-\mathrm{OH})$ groups $\left(3420 \mathrm{~cm}^{-1}\right)$ and $\mathrm{C}=\mathrm{C}\left(1586 \mathrm{~cm}^{-1}\right)$, while $\mathrm{GO}$ has been added with the stretching vibrations of $\mathrm{C}=\mathrm{O}\left(1736 \mathrm{~cm}^{-1}\right)$, carboxy $\mathrm{C}-\mathrm{O}\left(1414 \mathrm{~cm}^{-1}\right)$, epoxy $\mathrm{C}-\mathrm{O}\left(1220 \mathrm{~cm}^{-1}\right)$, and $\mathrm{C}-\mathrm{O}$ $\left(1100 \mathrm{~cm}^{-1}\right){ }^{34-36}$ In comparison, GNS mainly shows the stretching vibrations of hydroxyl $(-\mathrm{OH})$ groups and $\mathrm{C}=\mathrm{C} .^{34-36}$ The FTIR results imply that GNS was significantly reduced, and this is consistent to XRD results. Peaks below $900 \mathrm{~cm}^{-1}$ are usually not interpreted for they represent too complex a structural signature. ${ }^{32}$ Furthermore, the samples were examined by Raman spectroscopy, an essential tool to characterize graphene. ${ }^{37}$ As illustrated in Figure 2(e), the Raman spectra underwent changes along the graphite-GO-GNS process, similar to those observed in the graphite to amorphous carbon transition. ${ }^{38}$ The Raman spectra of the graphite show the in-phase vibration of the graphite lattice ( $\mathrm{G}$ band) at $1579 \mathrm{~cm}^{-1}$ and a weak D band at $1312 \mathrm{~cm}^{-1}$. The Raman spectra for GO present a broadened $\mathrm{G}$ band at $1592 \mathrm{~cm}^{-1}$, owing to the presence of isolated double bonds that resonate at higher frequencies than the $\mathrm{G}$ band of graphite. ${ }^{39}$ The $\mathrm{D}$ band of GO becomes evident and keeps at $1312 \mathrm{~cm}^{-1}$, indicating the reduction in size of the in-plane $\mathrm{sp}^{2}$ domains due to the extensive oxidation. ${ }^{40}$ As for the Raman spectra of GNS, the G and D band are located at 1596 and $1319 \mathrm{~cm}^{-1}$, respectively. Besides the similarities of Raman spectra between GO and GNS, it is noteworthy that the $\mathrm{D} / \mathrm{G}$ intensity ratio of GNS $(0.82)$ is, in comparison with the value $(0.78)$ of graphite, increased, indicating a decrease in the size of the in-plane $\mathrm{sp}^{2}$ domains and a partially ordered crystalline structure of GNS. ${ }^{38}$

The GNS powders were thereafter used to prepare metal oxide-GNS nanocomposites via $\mathrm{ALD}-\mathrm{SnO}_{2}$ under different cycles. The samples after 300-cycle ALD-SnO 2 at 200 and 400 ${ }^{\circ} \mathrm{C}$ were characterized by XRD, and their XRD spectra were compared with those of the pristine GNS, illustrated in Figure 3(a). The XRD results show that, in comparison to the pristine GNS, the sample produced at $200{ }^{\circ} \mathrm{C}$ shows no observable

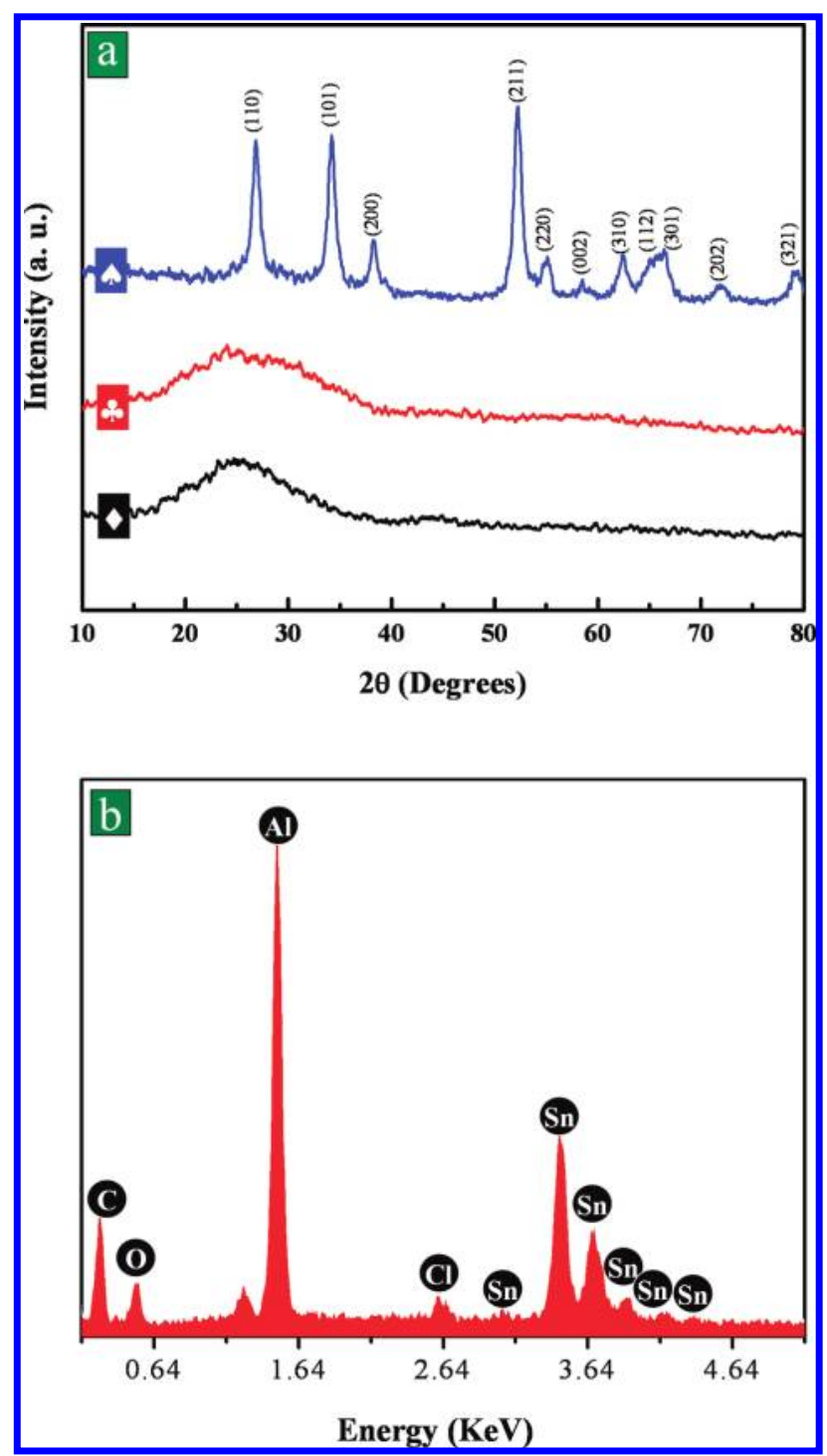

Figure 3. (a) XRD spectra of (diamond) GNS, (club) $\mathrm{SnO}_{2}$-GNS nanocomposites synthesized at $200{ }^{\circ} \mathrm{C}$, and (spade) $\mathrm{SnO}_{2}$-GNS nanocomposites synthesized at $400{ }^{\circ} \mathrm{C}$; (b) EDS spectra for $\mathrm{SnO}_{2}$-GNS nanocomposites synthesized at $200{ }^{\circ} \mathrm{C}$.

change while many characteristic peaks were with the sample produced at $400{ }^{\circ} \mathrm{C}$. To confirm the formation of $\mathrm{ALD}-\mathrm{SnO}_{2}$ at $200{ }^{\circ} \mathrm{C}$, the sample was examined by EDS equipped on FESEM, and EDS results (Figure 3(b)) revealed the presence of $\mathrm{Sn}, \mathrm{O}$, and $\mathrm{C}$ elements with the sample. The $\mathrm{Al}$ peak is resulted from the sample holder for EDS measurement. In addition, there is some $\mathrm{Cl}$ element resulting from unreacted functional groups. Thus, combined with the results disclosed by XRD, it was believed that amorphous $\mathrm{SnO}_{2}$ has been deposited on GNS. Alternatively, the XRD peaks with the sample produced at 400 ${ }^{\circ} \mathrm{C}$ were identified in the standard card and consistent with those reference values of crystalline $\mathrm{SnO}_{2}$ (Joint Committee on Powder Diffraction Standards (JCPDS) powder diffraction file (PDF) No. 41-1445). Thus, the ALD approach produced two different types of nanocomposites through simply adjusting growth temperatures: amorphous and crystalline $\mathrm{SnO}_{2}$-GNS composites at 200 and $400{ }^{\circ} \mathrm{C}$, respectively.

To further unveil the characteristics of the two types of nanocomposites produced at different temperatures, they were commonly examined by SEM and TEM. As shown in figure 4, ALD-SnO ${ }_{2}$ on GNS at $200{ }^{\circ} \mathrm{C}$ was performed with various ALD cycles. The SEM image for 100 cycles of $\mathrm{ALD}-\mathrm{SnO}_{2}$ (Figure 


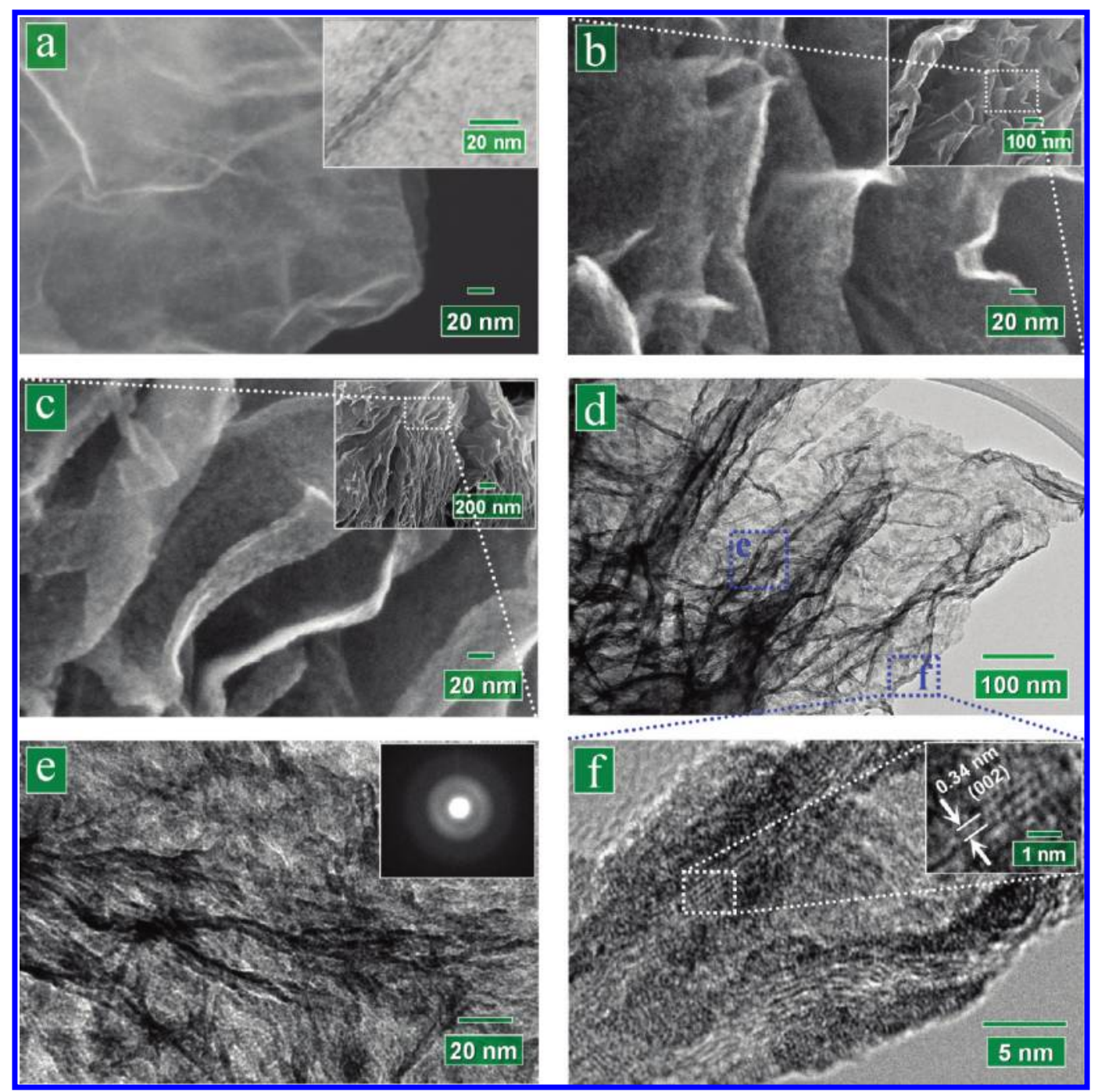

Figure 4. Amorphous $\mathrm{SnO}_{2}$-GNS nanocomposites: (a) $100 \mathrm{ALD}$ cycles of $\mathrm{SnO}_{2}$; (b) $200 \mathrm{ALD}$ cycles of $\mathrm{SnO}_{2}$; (c) $300 \mathrm{ALD}$ cycles of $\mathrm{SnO}{ }_{2}$; (d) low magnification TEM image of 300-cycle $\mathrm{SnO}_{2}$; (e) and (f) HRTEM images of 300-cycle $\mathrm{SnO}_{2}$.

4(a)) shows that GNS was covered with tiny nanoparticles $(\sim 3$ $\mathrm{nm}$, Figure SI-2(b), Supporting Information), which were confirmed by TEM (insert of Figure 4(a)). Upon 200 ALD cycles (Figure 4(b)), it was observed that GNS surface has been totally covered by $\mathrm{SnO}_{2}$ nanoparticles $(\sim 5 \mathrm{~nm}$, Figure SI-2(d), Supporting Information) of high density, and the as-synthesized $\mathrm{SnO}_{2}$-GNS composite remains the porous structure. In the case of 300 ALD cycles, as shown in Figure 4(c) by SEM image, we observed a thin film formed on GNS. Obviously, the ALD$\mathrm{SnO}_{2}$ on GNS surface experienced an island-like growth in the first $200 \mathrm{ALD}$ cycles at a growth temperature of $200{ }^{\circ} \mathrm{C}$ before the growing nanoparticles coalesced into a uniform layer. Additionally, it is also noteworthy that the ALD- $\mathrm{SnO}_{2}$ was deposited equally on both sides of a single graphene (as disclosed in Figure 4, parts (b) and (c)). The sample after 300cycle ALD- $\mathrm{SnO}_{2}$ was further examined by TEM, as shown in Figure 4(d)-(f). We can observe from Figure 4(d) that the nanocomposite retains the morphologies of GNS with numerous wrinkles. In addition, two local areas, as blue-circled as "e" and "f", were further shown in Figure 4(e),(f), respectively. With an increased magnification TEM image in figure 4(e), it is worth noting that GNS was uniformly coated, and selected area electron diffraction (SAED, insert of figure 4(e)) only shows the disordered nature of the composite. The HRTEM image in figure 4(f) further confirmed no crystalline structure with $\mathrm{SnO}_{2}$, but it is easy to observe the graphene stacked with 5-6 layers and the interlayer spacing keeps at $0.34 \mathrm{~nm}$ (insert of Figure 4(f)). On the basis of the above-discussed results, we can clearly conclude that amorphous $\mathrm{SnO}_{2}$-GNS nanocomposites were synthesized at a growth temperature of $200{ }^{\circ} \mathrm{C}$, exhibiting tunable morphologies of $\mathrm{SnO}_{2}$ component and unchangeable morphologies of GNS.

Following the results of amorphous $\mathrm{SnO}_{2}$-GNS nanocomposites prepared at $200{ }^{\circ} \mathrm{C}$, the results of crystalline $\mathrm{SnO}_{2}$-GNS nanocomposites prepared at $400{ }^{\circ} \mathrm{C}$ are shown in Figure 5. After an initial 100-cycle $\mathrm{ALD}-\mathrm{SnO}_{2}$, the sample in Figure 5(a) shows that GNS surface was deposited uniformly with numerous nanoparticles varying in the range from $10-20 \mathrm{~nm}$. An averaging on 100 nanoparticles accounts for a value of $\sim 13$ $\mathrm{nm}$ for the nanoparticle size. Figure 5(b) shows nanoparticles growing bigger with an average size of $\sim 27 \mathrm{~nm}$ after 200 ALD cycles, and Figure 5(c) shows ever-growing nanoparticles having an average size of $\sim 33 \mathrm{~nm}$ after 300 ALD cycles. Thus, we observed a nonlinear growth with nanoparticles. In addition, it is noteworthy that, at each stage of different ALD cycles, there were always some tiny particles newly appeared and the density of nanoparticles showed an increasing tendency, implying that $\mathrm{SnO}_{2}$ nanoparticles might not all nucleate at the same time. The underlying reason could be attributed to deficient exposure of some local surface areas to precursors during ALD processes, 


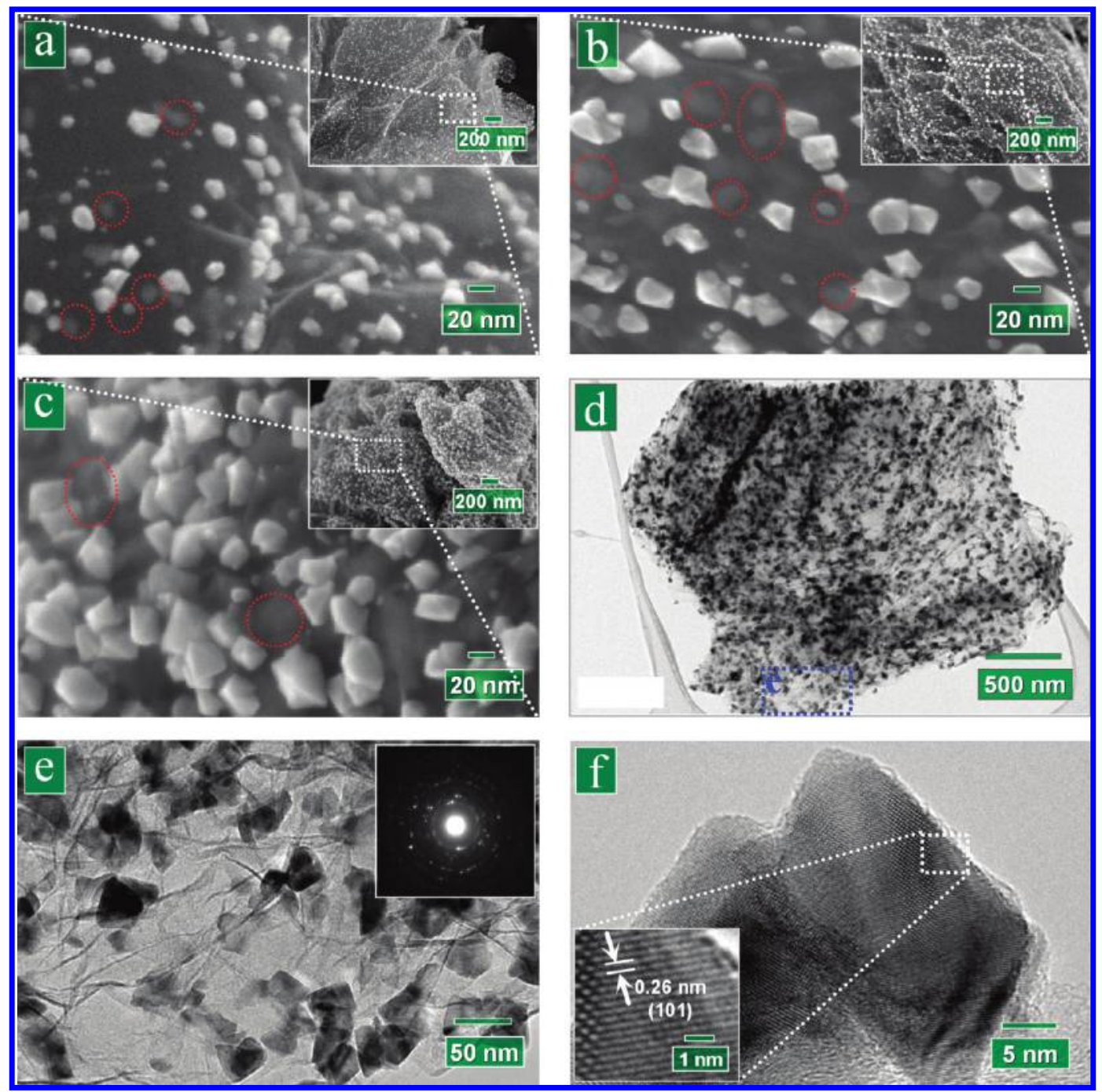

Figure 5. Crystalline $\mathrm{SnO}_{2}$-GNS nanocomposites: (a) 100 ALD cycles of $\mathrm{SnO}_{2}$; (b) $200 \mathrm{ALD}$ cycles of $\mathrm{SnO}$; (c) $300 \mathrm{ALD}$ cycles of $\mathrm{SnO}{ }_{2}$; (d) low magnification TEM image of 300-cycle $\mathrm{SnO}_{2}$; (e) and (f) HRTEM images of 300-cycle $\mathrm{SnO}_{2}$.

and then these sites nucleated later and experienced fewer ALD$\mathrm{SnO}_{2}$ cycles. In particular, we observed that, besides the nanoparticles sitting on top of the graphene surface, there are also numerous nanoparticles encapsulated inside GNS, as some are red-circled in Figure 5(a)-(c). The aforementioned results have three important implications: (1) the porous structure of GNS provided space for precursors to enter and thereby to deposit; (2) GNS consisted of only a few layers of graphene were functionalized in both sides; (3) as a gas-solid reaction system, ALD can provide well-controlled deposition through adjusting the number of ALD cycles. Furthermore, the sample after 300-cycle ALD-SnO 2 was further examined using TEM. Figure 5(d) revealed similar information as Figure 5(c), and a blue-circled part marked with "e" was enlarged in Figure 5(e). Clearly we can observe the nanoparticles located on the upside and downside of GNS. The insert of Figure 5(e) disclosed that the $\mathrm{SnO}_{2}$ nanoparticles are crystalline and were further examined by HRTEM in Figure 5(f). It was clearly shown that the $\mathrm{SnO}_{2}$ nanoparticles are with a characteristic lattice fringe of (101). Combined with XRD spectra (Figure 2(a)), we can conclude that the $\mathrm{SnO}_{2}$-GNS nanocomposites produced at $400{ }^{\circ} \mathrm{C}$ are with a crystalline $\mathrm{SnO}_{2}$ component, and $\mathrm{SnO}_{2}$ nanoparticles are tunable in size as well.

In the above-discussed results, we deduced that the ALD strategy is a facile approach to synthesize $\mathrm{SnO}_{2}$-GNS hybrid composites with controllable amorphous/crystalline phase as well as tunable morphologies of $\mathrm{SnO}_{2}$ component. It is worth noting that growth temperature plays an important role in determining the structural phases of $\mathrm{SnO}_{2}$, i.e., a low temperature contributes to amorphous phase while a high temperature is responsible for crystalline phase. Thus, it is necessary to explore the underlying mechanisms for a better understanding and manipulating the synthesis process. In this way, we explained the phenomena by applying the knowledge of surface chemistry and it is believed that surface reactions are temperaturedependent.

As stated above, ALD is a surface-controlled process. So, the initiation of an ALD process is highly dependent on the functional groups carried by pristine samples. As disclosed by FTIR spectra (Figure 2(d)), the as-synthesized GNS samples were dominantly attached with hydroxyl $(-\mathrm{OH})$ groups. Thus, the hydroxyl groups guaranteed the initiation of $\mathrm{ALD}-\mathrm{SnO}_{2}$, as described in Recation 2-A. To explain controllable structural phases of $\mathrm{SnO}_{2}$, however, we noticed that the corresponding surface reactions are temperature-dependent in nature. In this way, Puurunen ${ }^{41}$ made an excellent review on ALD processes of using metal chlorides and water as the precursors, and noticed that this sort of ALD process (e.g., $\mathrm{TiO}_{2}$, and $\mathrm{ZrO}_{2}$ ) experienced a phase-transition from amorphous films to crystalline nanoparticles when a threshold temperature $\left(300^{\circ} \mathrm{C}\right)$ was achieved. 


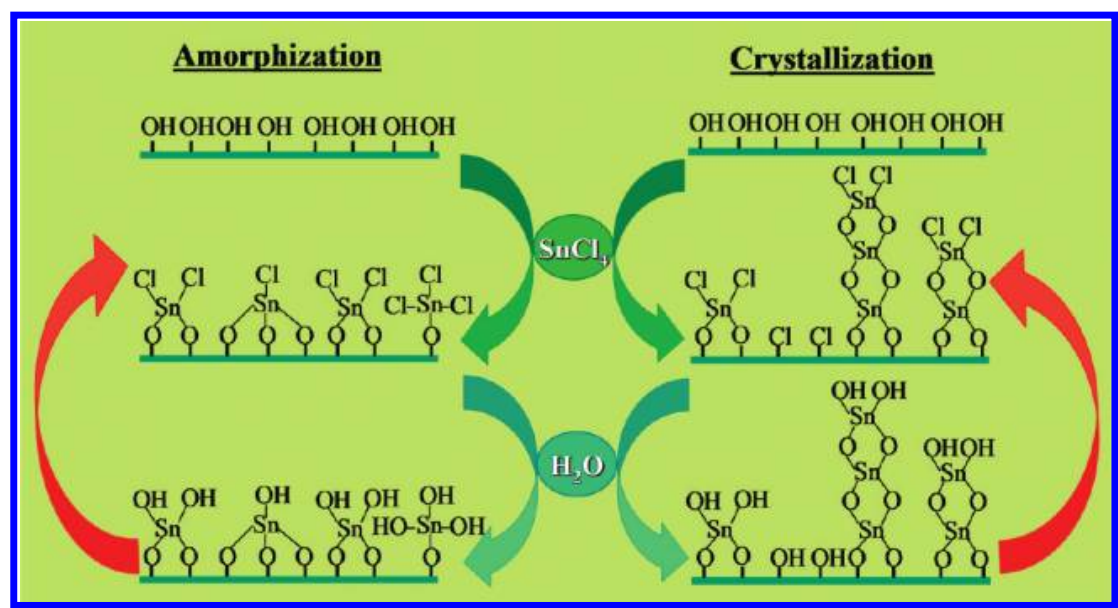

Figure 6. Schematic illustration of surface reactions occurred in $\mathrm{ALD}-\mathrm{SnO}_{2}$ due to different growth temperatures: (on left side) amorphization for $200{ }^{\circ} \mathrm{C}$, and (on the right side) crystallization for $400{ }^{\circ} \mathrm{C}$.

Furthermore, Puurunen proposed different underlying mechanisms for them: (a) ligand exchange (as shown in Reactions 2-A and 2-B) is the most prevalent mechanism responsible for amorphization at low temperature $\left(<300{ }^{\circ} \mathrm{C}\right)$; (b) a prominent two-step chlorination in the pulse of a metal chloride is responsible for crystallization at high temperature $\left(>300^{\circ} \mathrm{C}\right)$. To address the two-step chlorination potentially happened in ALD-SnO ${ }_{2}$, we proposed and described it for ALD-SnO $\mathrm{O}_{2}$ in the following reactions:

$$
\mathrm{Il}-\mathrm{OH}+\mathrm{SnCl}_{4}(\mathrm{~g}) \rightarrow \mathrm{II}-\mathrm{Cl}+\mathrm{Sn}(\mathrm{OH}) \mathrm{Cl}_{3}(\mathrm{~g})
$$

$$
\mathrm{II}-\mathrm{OH}+\mathrm{Sn}(\mathrm{OH}) \mathrm{Cl}_{3}(\mathrm{~g}) \rightarrow \mathrm{II}-\mathrm{Cl}+\mathrm{Sn}(\mathrm{OH})_{2} \mathrm{Cl}_{2}(\mathrm{~g})
$$

First, $\mathrm{SnCl}_{4}$ chlorinates the surface hydroxyl groups and form an intermediate hydroxychloride molecule $\left(\mathrm{Sn}(\mathrm{OH})_{2} \mathrm{Cl}_{2}\right)$ in two steps, as shown in Reactions 3-A1 and 3-A2. Then the hydroxychloride reacts with surface chlorine groups through its hydroxyl groups, as shown in Reaction 3-A3 as follows:

$$
2 \mathrm{ll}-\mathrm{Cl}+\mathrm{Sn}(\mathrm{OH})_{2} \mathrm{Cl}_{2}(\mathrm{~g}) \rightarrow \mathrm{II}-\mathrm{O}_{2}-\mathrm{SnCl}_{2}+2 \mathrm{HCl}(\mathrm{g})
$$

In particular, the chlorine groups on the right side of the former Reaction 3-A3 would still potentially react with hydroxychloride in a chain of reactions, as shown in the following Reaction 3-A4:

$$
\begin{gathered}
\mathrm{I}-\mathrm{O}_{2}-\mathrm{SnCl}_{2}+\mathrm{Sn}(\mathrm{OH})_{2} \mathrm{Cl}_{2}(\mathrm{~g}) \rightarrow \mathrm{II}-\left(\mathrm{SnO}_{2}\right)_{2} \mathrm{Cl}_{2}+ \\
2 \mathrm{HCl}(\mathrm{g}) \rightarrow \cdots \cdots \rightarrow \| \mathrm{I}-\left(\mathrm{SnO}_{2}\right)_{n} \mathrm{Cl}_{2}+2 \mathrm{HCl}(\mathrm{g})
\end{gathered}
$$

Thus, surface reactions at high temperature in a pulse of $\mathrm{SnCl}_{4}$ could contribute a formation of multilayer. It explained why the nanoparticles grew more quickly at high temperature than at low temperature after a same number of ALD cycles. In addition, it also provided the answers to the size-varied nanoparticles and the continuously newly appeared nanoparticles with a nonlinear growth mode, for some sites might be involved in reactions in a chain (as shown in Reaction 3-A4) while others were not in a certain pulse of $\mathrm{SnCl}_{4}$. However, the surface reaction happened in a pulse of $\mathrm{H}_{2} \mathrm{O}$ is still simple ligand exchange, which is the same as shown by Reaction 2-B:

$$
\mathrm{Il}-\mathrm{Cl}+\mathrm{H}_{2} \mathrm{O}(\mathrm{g}) \rightarrow \mathrm{II}-\mathrm{OH}+\mathrm{HCl}(\mathrm{g})
$$

To compare the differences in surface reactions incurred by different temperatures, it is believed that the half reactions occurred in the pulse of $\mathrm{H}_{2} \mathrm{O}$ are independent of temperature, as commonly indicated by Reactions 2-B and 3-B. However, the half reactions occurred in the pulse of $\mathrm{SnCl}_{4}$ are temperaturedependent, as described in Reaction 2-A for low temperature $\left(200{ }^{\circ} \mathrm{C}\right.$ ) and in Reactions 3 -A1 to 3 -A4 for high temperature $\left(400{ }^{\circ} \mathrm{C}\right)$. To further understand the different mechanisms incurred by growth temperature, we schematically illustrated the growth mechanisms in the following Figure 6. On the left side of Figure 6, surface reactions were illustrated for amorphization of deposited materials based on ligand exchange, and they are self-limiting in nature. On the right side of Figure 6 for crystallization, however, the surface reactions (as stated in above Reactions 3-A1 to 3-A4) are not self-limiting in the pulse of $\mathrm{SnCl}_{4}$ while the ones are self-limiting in the pulse of $\mathrm{H}_{2} \mathrm{O}$, leading to the formation of mutilayers dependent on reactive sites in one ALD cycle. In particular, as noticed by Puurunen, ${ }^{41}$ the transition between ligand exchange and chlorinatnion might happen suddenly when the growth temperature is over a certain threshold, which is suggested around $300{ }^{\circ} \mathrm{C}$. Obviously, it is growth temperature that influences the structural phases of deposited $\mathrm{SnO}_{2}$ via surface chemistry.

In addition, it is noteworthy that the $\mathrm{ALD}-\mathrm{SnO}_{2}$ at $200{ }^{\circ} \mathrm{C}$ experienced an island-like growth in the first 200 cycles before a uniform layer was formed by coalescence of growing nanoparticles. It should be particularly clarified that the islandlike growth mode at $200{ }^{\circ} \mathrm{C}$ is in essence different from the formation of crystalline $\mathrm{SnO}_{2}$ nanoparticles at $400{ }^{\circ} \mathrm{C}$. The island formation at $200{ }^{\circ} \mathrm{C}$ is mainly caused by the poor reactivity of the template surface ${ }^{42}$ and the growth mode of $\mathrm{SnO}_{2}$ is substrateinhibited by a lower $\mathrm{OH}$ group density. Thus, the growth rate is low in the beginning. However, the growth rate should be increased to a constant value while the islands coalesce into a film with increased ALD cycles. However, the formation of nanoparticles at $400{ }^{\circ} \mathrm{C}$ is not restricted by the reactivity of the template surface but due to the chlorination process in which the multilayer formation occurs. 


\section{Conclusions}

We applied a nonaqueous ALD approach for synthesis of MO-GNCs, which was successfully exemplified with the preparation of $\mathrm{SnO}_{2}$-GNS hybrid composites using $\mathrm{SnCl}_{4}$ and $\mathrm{H}_{2} \mathrm{O}$ as the ALD precursors. This strategy exhibited many unique advantages in synthesizing MO-GNCs. First of all, it is a facile vapor route, which needs no further post-treatment (such as, filtration, washing, and annealing) widely used in solutionbased methods. ${ }^{15-19}$ Second, the ALD approach can well tune and control the deposited metal oxide on both morphologies and structural phases. As demonstrated in this work, the asdeposited $\mathrm{SnO}_{2}$ was shown with nanoparticles/films as well as in form of amorphous/crystalline phases through adjusting the ALD cycling numbers and suitable growth temperatures. It has not been reported that both amorphous and crystalline $\mathrm{SnO}_{2}$ have been synthesized with a single method in earlier studies. Third, this ALD approach has the potential for mass production. As reported earlier by George's group, ${ }^{43,44}$ ALD can be combined with fluidization technology ${ }^{43}$ or rotary devices ${ }^{44}$ for coating nanopartilces of large quantities. Thus, it is reasonable to believe that MO-GNCs can be produced in large quantities with this ALD route. Specifically, the as-synthesized $\mathrm{SnO}_{2}-\mathrm{GNS}$ hybrid nanocomposites can be important candidates for many applications, such as Li-ion batteries, ${ }^{18-20}$ gas-sensing, ${ }^{45}$ as well as solar cells. ${ }^{46}$ The controllable amorphous/crystalline phase of $\mathrm{SnO}_{2}$ would provide more choices for seeking a better performance of the aforementioned applications and is also potentially appealing for academic curiosity.

Acknowledgment. This research was supported by the Natural Science and Engineering Research Council of Canada (NSERC), Canada Research Chair (CRC) Program, Canadian Foundation for Innovation (CFI), Ontario Research Fund (ORF), Early Researcher Award (ERA) and the University of Western Ontario.

Supporting Information Available: SEM images for natural graphite and graphite oxide; SEM images for amorphous $\mathrm{SnO}_{2-}$ GNS nanocomposites. This material is available free of charge via the Internet at http://pubs.acs.org.

\section{References and Notes}

(1) Su, D. S.; Schlögl, R. ChemSusChem 2010, 3, 136.

(2) Spitalsky, Z.; Tasis, D.; Papagelis, K.; Galiotis, C. Prog. Polvm. Sci. 2010, 35, 357 .

(3) Sun, L.; Gibson, R. F.; Gordaninejad, F.; Suhr, J. Compos. Sci. Technol. 2009, 69, 2392.

(4) Zeng, Z.; Zhou, X.; Huang, X.; Wang, Z.; Yang, Y.; Zhang, Q.; Boey, F.; Zhang, H. Analvst 2010, 135, 1726.

(5) Novoselov, K. S.; Geim, A. K.; Morozov, S. V.; Jiang, D.; Zhang, Y.; Dubonos, S. V.; Grigorieva, I. V.; Firsov, A. A. Science 2004, 306, 666.

(6) Stankovich, S.; Dikin, D. A.; Dommett, G. H. B.; Kohlhaas, K. M.; Zimney, E. J.; Stach, E. A.; Piner, R. D.; Nguyen, S. T.; Ruoff, R. S. Nature 2006, 442, 282.

(7) Eda, G.; Unalan, H. E.; Rupesinghe, N.; Amaratunga, G. A. J.; Chhowalla, M. Appl. Phvs. Lett. 2008, 93, 233502.

(8) Wei, T.; Luo, G.; Fan, Z.; Zheng, C.; Yan, J.; Yao, C.; Li, W.; Zhang, C. Carbon 2009, 47, 2290.
(9) Qi, X.; Pu, K.-Y.; Zhou, X.; Li, H.; Liu, B.; Boey, F.; Huang, W.; Zhang, H. Small 2010, 6, 663.

(10) Li, Y.; Gao, W.; Ci, L.; Wang, C.; Ajayan, P. M. Carbon 2010, 48,1124

(11) Zhou, X.; Huang, X.; Qi, X.; Wu, S.; Xue, C.; Boey, F. Y. C.; Yan, Q.; Chen, P.; Zhang, H. J. Phvs. Chem. C 2009, 113, 10842.

(12) Guo, S.; Dong, S.; Wang, E. ACS Nano 2010, 4, 547.

(13) Huang, X.; Zhou, X.; Wu, S.; Wei, Y.; Qi, X.; Zhang, J.; Boey, F.; Zhang, H. Small 2010, 6, 513.

(14) Williams, G.; Seger, B.; Kamat, P. V. ACS Nano 2008, 2, 1487.

(15) Wang, D.; Choi, D.; Li, J.; Yang, Z.; Nie, Z.; Kou, R.; Hu, D.;

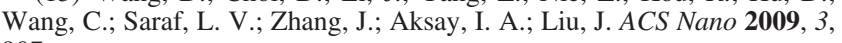
907.

(16) Lee, J. M.; Pyun, Y. B.; Yi, J.; Choung, J. W.; Park, W. I. J. Phvs. Chem. C 2009, 113, 19134.

(17) Wu, J.; Shen, X.; Jiang, L.; Wang, K.; Chen, K. Appl. Surf. Sci. 2010, 256, 2826.

(18) Yao, J.; Shen, X.; Wang, B.; Liu, H.; Wang, G. Electrochem. Commun. 2009, 11, 1849.

(19) Wang, D.; Kou, R.; Choi, D.; Yang, Z.; Nie, Z.; Li, J.; Saraf, L. V.; Hu, D.; Zhang, J.; Graff, G. L.; Liu, J.; Pope, M. A.; Aksay, I. A. $\underline{A C S}$ Nano 2010, 4, 1587.

(20) Paek, S. M.; Yoo, E.; Honma, I. Nano Lett. 2009, 9, 72.

(21) George, S. M. Chem. Rev. 2010, 110, 111.

(22) Knez, M.; Nielsch, K.; Niinistö, L. Adv. Mater. 2007, 19, 3425.

(23) Kim, H.; Lee, H. B. R.; Maeng, W. J. Thin Solid Films 2008, 517 , 2563

(24) Li, Z.; Barry, S. T.; Gordon, R. G. Inorg. Chem. 2005, 44, 1728. (25) Rosental, A.; Tarre, A.; Gerst, A.; Uustare, T.; Sammelselg, V. Sens. Actuators, B 2001, 77, 297.

(26) Takeuchi, T.; Shoji, K.; Tadano, T.; Doteshita, I.; Onodera, S. $\underline{\text { Thin }}$ Solid Films 2003, 442, 98.

(27) Rosental, A.; Tarre, A.; Gerst, A.; Sundqvist, J.; Hårsta, A.; Aidla, A.; Aarik, J.; Sammelselg, V.; Uustare, T. Sens. Actuators B 2003, 93, 552. (28) Du, X.; Du, Y.; George, S. M. J. Vac. Sci. Technol. A 2005, 23, 581.

(29) Hummers, W. S.; Offeman, R. E. J. Am. Chem. Soc. 1958, 80, 1339 .

(30) Schniepp, H. C.; Li, J. L.; McAllister, M. J.; Sai, H.; HerreraAlonso, M.; Adamson, D. H.; Prud'homme, R. K.; Car, R.; Saville, D. A.; Aksay, I. A. J. Phys. Chem. B 2006, 110, 8535.

(31) Celzard, A.; Mareche, J. F.; Furdin, G. Prog. Mater. Sci. 2005, 50,

(32) Lee, D. W.; Santos, L. D. L.; Seo, V. J. W.; Felix, L. L.; Bustamante, A.; Cole, D. J. M.; Barnes, C H. W. J. Phvs. Chem. B 2010, $114,5723$.

(33) Tang, L.; Wang, Y.; Li, Y.; Feng, H.; Lu, J.; Li, J. Adv. Funct. Mater. 2009, 19, 2782.

(34) Chen, W.; Yan, L.; Bangal, P. R. Carbon 2010, 48, 1146.

(35) Singh, V. K.; Patra, M. K.; Manoth, M.; Gowd, G. S.; Vadera,

S. R.; Kumar, N. New Carbon Mater. 2009, 24, 147.

(36) Nethravathi, C.; Nisha, T.; Ravishankar, N.; Shivakumara, C.; Rajamathi, M. Carbon 2009, 47, 2054.

(37) Rao, C. N. R.; Biswas, K.; Subrahmanyam, K. S.; Govindaraj, A. J. Mater. Chem. 2009, 19, 2457.

(38) Ferrari, A. C.; Robertson, J. Phys. Rev. B 2000, 61, 14095.

(39) Kudin, K. N.; Ozbas, B.; Schniepp, H. C.; Prud'homme, R. K.; Aksay, I. A.; Car, R. Nano Lett. 2008, 8, 36.

(40) Stankovich, S.; Dikin, D. A.; Piner, R. D.; Kohlhaas, K. A.; Kleinhammes, A.; Jia, Y.; Wu, Y.; Nguyen, S. T.; Ruoff, R. S. Carbon 2007, 45, 1558 .

(41) Puurunen, R. L. Chem. Vap. Deposition 2005, 11, 79.

(42) Puurunen, R. L.; Vandervorst, W. J. Appl. Phvs. 2004, 96, 7686.

(43) Hakim, L. F.; George, S. M.; Weimer, A. W. Nanotechnology 2005, $16, \mathrm{~S} 375$.

(44) Cavanagh, A. S.; Wilson, C. A.; Weimer, A. W.; George, S. M. Nanotechnology 2009, 20, 255602.

(45) Batzill, M. Sensors 2006, 6, 1345.

(46) Snaith, H. J.; Ducati, C. Nano Lett. 2010, 10, 1259.

JP105852H 